\title{
Characterization of Pectin from Pulp and Peel of Ugandan Cooking Bananas at Different Stages of Ripening
}

\author{
Diriisa Mugampoza ${ }^{1}$, Samuel Gafuma ${ }^{1}$, Peacekind Kyosaba ${ }^{2} \&$ Richard Namakajjo ${ }^{3}$ \\ ${ }^{1}$ Department of Food Technology, Faculty of Science, Kyambogo University, Kampala, Uganda \\ ${ }^{2}$ School of Management and Entrepreneurship, Kyambogo University, Kampala, Uganda \\ ${ }^{3}$ Uganda National Bureau of Standards (UNBS) Laboratories, Kampala, Uganda \\ Correspondence: Samuel Gafuma, Department of Food Technology, Kyambogo University, Kampala. P. O. Box \\ 1 Kyambogo, Kampala, Uganda. Tel: 256-773-883-895/256-704-987-849. E-mail: gafumasam@yahoo.com
}

Received: June 4, 2020

doi:10.5539/jfr.v9n5p67
Accepted: July 20, $2020 \quad$ Online Published: September 9, 2020

URL: https://doi.org/10.5539/jfr.v9n5p67

\begin{abstract}
East African highland cooking bananas (EA-AAA) are a staple food and major source of calories for Ugandans. Cooking bananas are considerably wasted along the postharvest chain majorly due to poor handling and ripening. Banana waste is a potential source of secondary products such as pectin, wine, beer to mention a few. The aim of this study was to extract and characterize pectin from selected cooking bananas at various stages of ripening in order to assess their potential for commercial pectin production. Pectin was extracted from the bananas at five stages of ripening i.e. stages 0 (green maturity), 1, 2, 5 and 7 . Extracted pectin at stages $2,5 \& 7$ was characterized.

Pectin yield from banana pulp decreased significantly with ripening $(\mathrm{P}<0.05)$ from between 18.1 to $22.65 \%$ at green maturity to between 0.65 to $1.28 \%$ at stage 7 of ripening. Pectin yield from banana peels was generally lower decreasing from between 5.34 to $6.61 \%$ at green maturity to between 1.01 to $1.38 \%$ at stage 7 . The equivalent weight (1774 to 10144) of the pectin at selected stages of ripening was not significantly different $(\mathrm{P}>0.05)$ except individually. Methoxyl content was not significantly different among cultivars $(\mathrm{P}>0.05)$, however, it increased significantly through ripening stages $(\mathrm{P}<0.05)$. Anhydrouronic acid (AUA) ranged between 24.51 to $67.38 \%$ and increased with stage of ripening. AUA of pectin from pulp and peel did not differ significantly $(\mathrm{P}>0.05)$. The degree of esterification at each of the three stages was generally high (77 to $94 \%)$ implying high gelling power.

These results showed that purity of pectin increases while yield decreases with ripening and that banana pectin has a high degree of esterification implying rapid set pectin. Thus, banana peel and pulp can be good sources of industrial pectin.
\end{abstract}

Keywords: banana pulp and peel, cooking bananas, pectin extraction \& characterization, ripening stages

\section{Introduction}

Bananas are the fourth most important food crop in the world after rice, wheat and corn (Arumugam \& Manikandan, 2011). They are an important staple food particularly in tropical countries where they contribute to food security (Kabahenda, et al., 2010). The banana fruit is a good source of energy and minerals and is normally consumed fresh or processed to make products such as crisps, flour/powder, jam and wine.

Uganda is the world's largest producer and consumer of cooking bananas (Kabahenda et al., 2010) of the East African Highland (EA-AAA) genotype. Most cooking bananas (Matooke) are harvested and consumed at green maturity (Gafuma, Byarugaba-Bazirake, \& Mugampoza, 2018). The fruits are peeled and steamed in banana leaves which are then mashed to make a thick paste that is served with sauce. Sometimes, whole fingers are boiled with beans, ground nuts or meat to make a mixture (Katogo). Thus, large volumes of peel are derived and either given to animals as feed or discarded on waste bins resulting in environmental pollution particularly in the urban and peri-urban areas. Moreover, Matooke are normally stored at ambient conditions $\left(\sim 25^{\circ} \mathrm{C}\right)$ which accelerate ripening resulting in rejection on the market and transformed into agricultural waste. The high physical and economic losses coupled with minimum processing calls for intervention studies that could add value to waste Matooke. Edible by-products can be generated from banana peel and pulp as part of the waste 
stream recovery (Min, et al., 2011). These materials could also be potential sources of high-quality pectin. Pectin is the second most important structural component of bananas that affects their mechanical or structural and functional properties in the living tissue where it causes firmness but also during cooking where it is involved in softening (Parre \& Geitmann, 2005; Gafuma et al, 2018) particulalry in the presence of water as it undergoes solubilization.

Most of the pectin used in the food industry in Uganda is imported. Commercially, pectin is extracted from raw materials such as apple pomace or citrus peels by acid hydrolysis at high temperatures. The $\mathrm{pH}$, temperature and extraction method affect pectin yield and quality (Wang, et al., 2007). Extraction and characterization of pectin have been studied for many plant materials including pumpkins, soy hull, peach pomace, sugar beet, Krueo Ma Noy (Cissampelos pareira; a herb traditionally used in warm regions of Asia, East Africa and South America), apple pomace, mangoes, cocoa husks, citrus peel, jackfruit waste and Saba banana waste (Castillo-Israel, Diasanta, Lizardo, Dizon, \& Mejico, 2015). Therefore, ripe matooke could be used as alternative source of commercial pectin. Banana peels account for $40 \%$ of the total weight of the fresh banana fruit (Naggarajaiah \& Prakash, 2011). Therefore, the need to examine whether or not banana peel could be a better source of high-quality pectin relative to pulp, cannot be overemphasized.

The stage of ripening at which banana peel and pulp contain the highest levels of high-quality pectin needs to be established in order to maximize pectin extraction from banana waste streams. Therefore, the aim of this study was to extract and characterize pectin from cooking banana pulp and peel at green maturity and selected stages of ripening.

\section{Materials and Methods}

\subsection{Materials}

Three Ugandan indigenous cooking banana cultivars (EA-AAA genome) were investigated basing on their abundance on the market. These include Musakala, Mpologoma, and Nakitembe. For each cultivar, green mature bananas were bought from Kawanda Agricultural Research Institute and directly transported to Kyambogo University Food laboratory for pectin extraction and characterization. All chemicals and reagents used were of laboratory grade and purchased from LabX Scientific Uganda Ltd.

\subsection{Preparation and Ripening of Bananas}

Second and third clusters were used to prepare bulk samples for each cultivar (Dadzie \& Orchard, 1997). All samples were washed with portable water and ripened by covering with a tarpaulin while monitoring relative humidity $(57-85 \%)$ and temperature $\left(24-31^{\circ} \mathrm{C}\right)$ every after $8 \mathrm{~h}$. Samples which attained the desired level of ripeness (stages 1, 2, 5 and 7) based on the scale adopted from SH Prat's and Company (Luton UK) (Figure 1) were selected for pectin extraction and characterization. Unripe green mature bananas (stage 0) were used as the control.

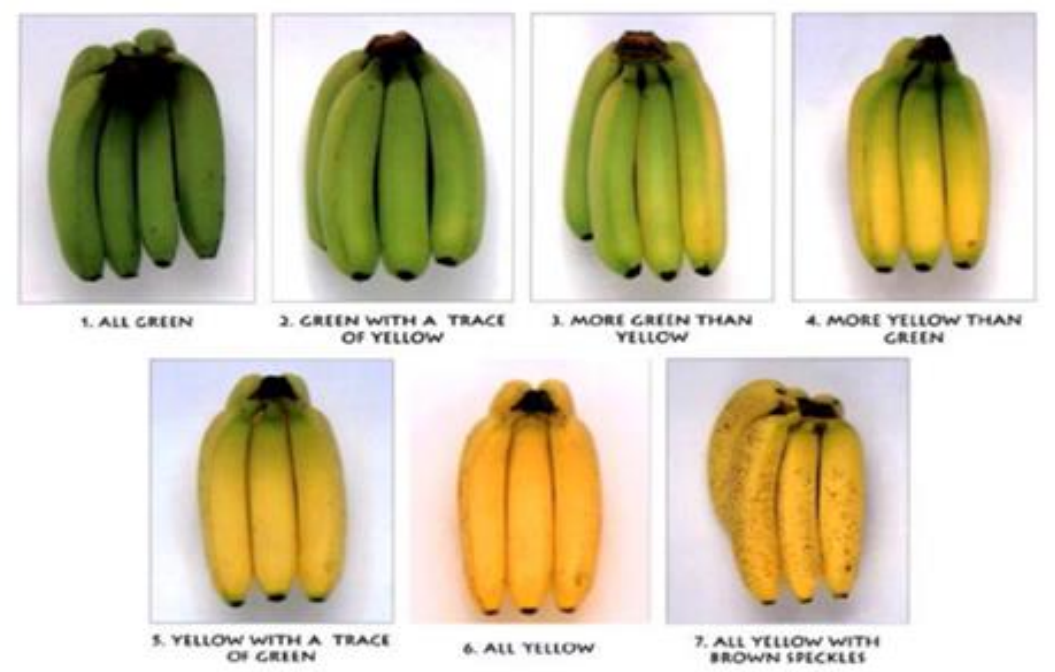

Figure 1. Colour chart used for grading of ripening bananas. Adopted from SH Pratt's \& co, Luton, UK 


\subsection{Extraction of Pectin}

Pectin was extracted using hot dilute $\mathrm{HCl}$ adopted from Pratik, Sheetal \& Teja. (2017) with some modifications. Bananas samples at stages 0 (green maturity), 1, 2, 5 and 7 of ripening were sectioned into pulp and peel using a stainless-steel knife. Then, $50 \mathrm{~g}$ of each of the pulp and peel was separately weighed and crushed in a coffee grinder (Geepas, GCG289, Japan) to obtain a homogenous paste. The paste was mixed with 2.5 litres of boiling water acidified with $0.5 \mathrm{ml}$ of $11.91 \mathrm{M} \mathrm{HCl}$ to give a $\mathrm{pH}$ of $2.2 \pm 0.1$, followed by addition of $20 \mathrm{~g}$ of washed nylon threads as the filter aid. The same water was used to wash out the banana paste residue on the sides of the grinder and added to the mixture. The mixture was heated at $95-100^{\circ} \mathrm{C}$ for 30 min with constant stirring. Then, the mixture was filtered and the residue was washed with 1 litre of boiling water. The filtrate was cooled before adding 2 litres of $96 \%$ ethanol containing $0.2 \mathrm{ml}$ of $11.91 \mathrm{M} \mathrm{HCl} /$ litre. The mixture was slowly stirred and left to stand for $40 \mathrm{~min}$ to precipitate the pectin and then filtered through a fine nylon cloth. The precipitate was collected on a pre- weighed Petri dish, weighed again and dried in the air-drying oven (GenLab $12 \mathrm{~m} 064, \mathrm{UK}$ ) at $50^{\circ} \mathrm{C}$ for $16 \mathrm{~h}$. The dried pectin extract was cooled in a desiccator, weighed and pulverized in a grinder (Geepas) to a fine powder which was stored at room temperature for further use. Pectin yield was calculated as follows:

$$
\text { Pectin yield }=\frac{E P \times 100}{B i}
$$

Where $\mathrm{Ep}=$ extracted pectin in grams; $\mathrm{Bi}=$ Weight of banana pulp/peel in grams.

\subsection{Characterization of the Extracted Pectin}

Characterization was done for pectin extracts at stages 2, 5 and 7 of ripening since at these stages, the pectin is expected to have reducing degree of contamination from other polysaccharides such as cellulose, hemicellulose, starch and lignin. Equivalent weight, Methoxyl content, Anhydrouronic acid, and degree of esterification were determined using methods by (Owens, et al., 1952) adopted from Castillo-Israel et al. (2015).

\subsubsection{Equivalent Weight}

The equivalent weight (Eq. wt) of pectin extract was determined according to the formula adopted from Castillo-Israel et al. (2015). Approx. $0.1 \mathrm{~g}$ of pectin extract was weighed into a $250 \mathrm{ml}$ conical flask and $1 \mathrm{ml} 99 \%$ ethanol (v/v) was added. Approx. $0.5 \mathrm{~g}$ of sodium chloride and $60 \mathrm{ml}$ of distilled water were added and heated in a water bath (Stuart SWB24D, UK) for $30 \mathrm{~min}$ at $45^{\circ} \mathrm{C}$. Finally, 2 drops of phenol red (Sigma-Aldrich, USA) were added and the solution titrated against $0.05 \mathrm{~N} \mathrm{NaOH}$. The end of the titration was indicated by development of a purple color and the titre volume recorded. Equivalent weight was calculated according to the following formula:

$$
\text { Equivalent weight }=\frac{\text { Weight of sample } \times 1000}{\text { ml of } \mathrm{NaOH} \times \text { Normality of } \mathrm{NaOH}}
$$

\subsubsection{Methoxyl Content (MeO)}

Methoxyl content was determined according to the formula adopted from Castillo-Israel et al. (2015). The neutral solution containing $0.5 \mathrm{~g}$ pectin extract from equivalent weight determination was used. To the neutral solution, $25 \mathrm{ml}$ of $0.25 \mathrm{~N}$ sodium hydroxide was added and mixed thoroughly. The solution was kept in a flask with a stopper at room temperature for $30 \mathrm{~min}$. Then, $25 \mathrm{ml}$ of $0.25 \mathrm{~N} \mathrm{HCl}$ was added and titrated with $0.1 \mathrm{~N}$ $\mathrm{NaOH}$ until a purple color was observed. Methoxyl content was calculated using the following formula:

\subsubsection{Anhydrouronic Acid (AUA)}

$$
\text { Methoxyl content }(\%)=\frac{m l \text { of alkali } x \text { Normality of alkali } \times 3.1}{\text { weight of sample }(g)}
$$

Estimation of AUA was performed by making use of the titration volumes in equivalent weight and methoxyl content determinations. Hence, total AUA was determined using the following formula adopted from Castillo-Israel et al. (2015).

$$
\text { Percentage (\%)AUA }=\frac{176 * 0.1 z * 100}{w * 1000}+\frac{176 * 0.1 y * 100}{w * 1000}
$$

Where the molecular weight unit of $\mathrm{AUA}=176 \mathrm{~g} ; \mathrm{z}=\mathrm{ml}$ of $\mathrm{NaOH}$ from the equivalent weight determination; $\mathrm{y}$ $=\mathrm{ml}$ of $\mathrm{NaOH}$ from methoxyl content determination and $\mathrm{w}=$ weight of the sample. 


\subsubsection{Degree of Esterification (DE)}

DE of pectin extract was determined on the basis of methoxyl and AUA content (Castillo-Israel et al., 2015) and calculated using the following formula:

\subsubsection{Ash Content}

$$
\% D E=\frac{176 * M e o}{31 * \% A U A} * 100
$$

The ash content of pectin extract was determined using method No. 923.3 of AOAC (2012) with modifications. One gram of pectin extract was ground to pass a 75-micron mesh screen and placed into a tared platinum crucible, then ignited in a muffle furnace (Carbolite AAF1100, Germany) at $550^{\circ} \mathrm{C}$ for $6 \mathrm{~h}$. The crucible containing ash was cooled in a desiccator and weighed. The ash content was calculated using the following formula:

\subsection{Data Analysis}

$$
\text { Ash content }(\%)=\frac{\text { weight of ash } \times 100}{\text { weight of pectin }}
$$

Parametric statistics (means \pm standard errors of means) and one-way analysis of variance (ANOVA) were computed using Predictive Analytical Software (PASW), v.23 for three independent replicates. Means were separated using Turkey test after analysis with GraphPad version 7. The P-values were set at $\mathrm{p}<0.05$.

\section{Results}

\subsection{Pectin Yield at different Stages of Ripening}

There was a significant decrease in pectin yield $(\mathrm{P}<0.05)$ from the pulp of selected banana cultivars with increase in ripening (Figure 2). Pectin yield (wet basis) decreased from 22.65, $21.38 \& 18.1 \%$ at green maturity to 1.19 , $1.28 \& 0.65 \%$ at stage 7 of ripening for Nakitembe (NKT), Musakala (MUS) \& Mpologoma (MPO), respectively. Pectin yield from banana peel was generally low and decreased from 5.83, $6.61 \& 5.34 \%$ to $1.01,1.38$ \& $1.08 \%$ for NKT, MUS and MPO, respectively.

Pectin yield was significantly higher $(\mathrm{P}<0.05)$ in pulp than in the peel particularly at stages 0 and 1 ; while at stage 2, 5 and 7 the yield from both pulp and peel was not significantly different $(\mathrm{P}>0.05)$. However, pectin yield from banana peel at stage 0 was not significantly different $(\mathrm{P}>0.05)$ from that of stages 2,5 and 7 of ripening.

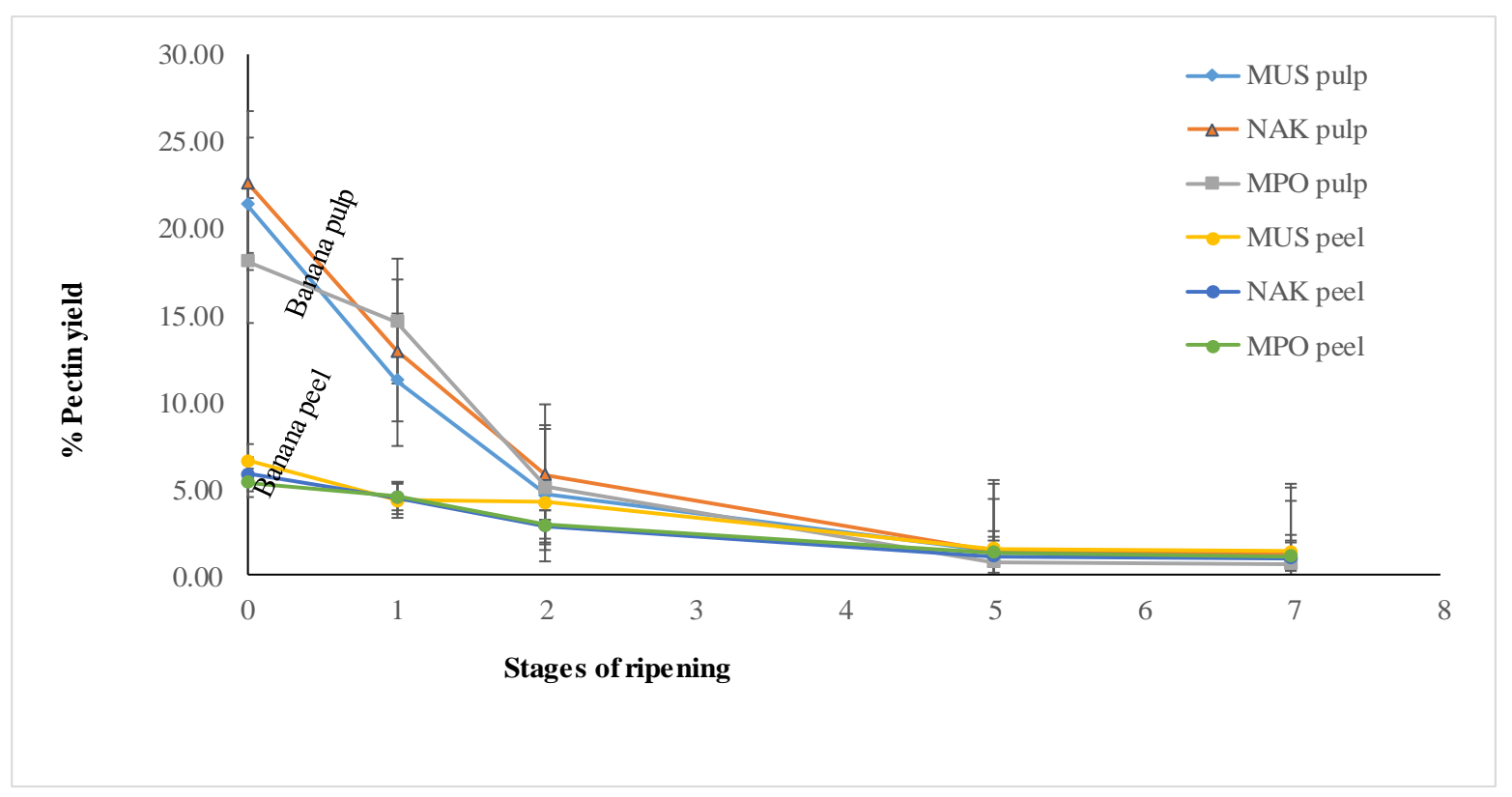

Figure 2. Changes in pectin yield from pulp and peel of selected cooking banana cultivars at different stages of ripening. Stage $0=$ Green maturity 


\subsection{Characterization of Pectin Extract}

\subsubsection{Equivalent Weight (eq. wt)}

Equivalent weight at each of stages 2, 5 and 7 was generally high (Figure 3). Equivalent weight of pectin from ripe banana pulp ranged from 1903 to 6421 while that of pectin from ripe banana peel ranged from 1774 to 10 $144 \mathrm{~g}$ per mol. Pectin from Mpologoma peel and pulp had significantly higher equivalent weight than that from Musakala and Nakitembe ( $\mathrm{P}<0.05)$. The eq. wt. of pectin from pulp and peel of Musakala at the three stages of ripening was not significantly different $(\mathrm{P}>0.05)$. On the other hand, equivalent weight of pectin from Mpologoma was initially very high and decreased significantly $(\mathrm{P}<0.05)$ with ripening while that of pectin from Musakala did not significantly change ( $\mathrm{P}>0.05)$.

At stage 2 of ripening, the eq. wt. of pectin from Nakitembe pulp was 1970.9, which was the lowest followed by Musakala with 2041.0 and Mpologoma the highest with $12657.5 \mathrm{~g} / \mathrm{mol}$. At stage 5, the equivalent weight of pectin from Nakitembe was 1903.8, Musakala was 2051.9, and Mpologoma was $6421.4 \mathrm{~g} / \mathrm{mol}$. At stage 7, equivalent weight of pectin from Musakala was 1986.4, that of pectin from Nakitembe was 3657.5 and that of pectin from Mpologoma was $4500.0 \mathrm{~g} / \mathrm{mol}$. The equivalent weight of pectin from banana peel at stage 2 was 10 $144.0 \mathrm{~g} / \mathrm{mol}$ (Mpologoma), 4878.1 (Nakitembe) and $1783.0 \mathrm{~g} / \mathrm{mol}$ (Musakala). At stage 5 and 7 the equivalent weights of pectin from ripe banana peel was 1780.0 and 2556.3 for Nakitembe; 2085.0 and 1774.5 for Musakala and 5804.3 and $6384.4 \mathrm{~g} / \mathrm{mol}$ for Mpologoma respectively.

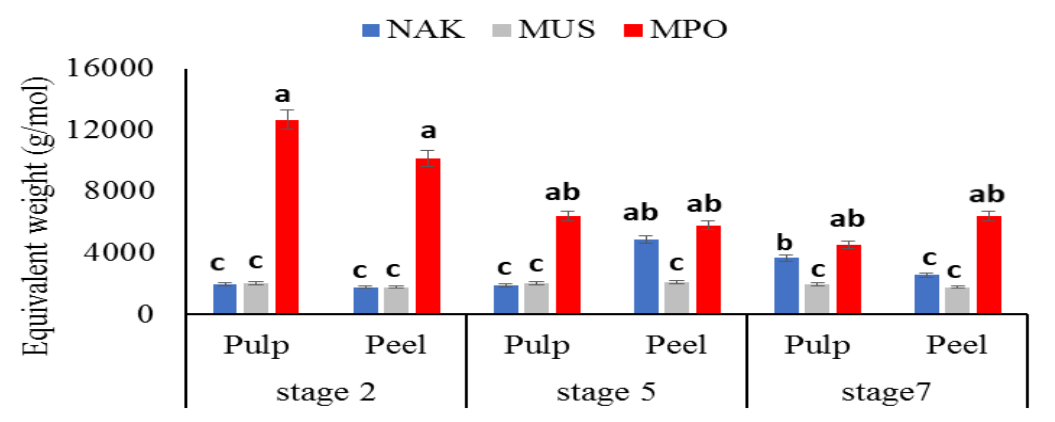

Figure 3. Equivalent weight of pectin from peel and pulp of selected cooking banana cultivars at different stages of ripening. Bars with different superscript letters are significantly different $(\mathrm{P}<0.05)$. NKT, Nakitembe; MUS,

Musakala; MPO, Mpologoma

\subsubsection{Methoxyl Content}

The methoxyl content of pectin from ripening banana pulp and peel was not significantly different $(\mathrm{P}>0.05)$ and generally increased through the ripening stages (Figure 4). Methoxyl content of pectin from banana peel ranged from 4.07 to $11.02 \%$ while that from banana pulp ranged from 3.67 to $8.21 \%$ across the ripening stages. Methoxyl content of pectin from banana pulp at stage 2 of ripening for all the three cultivars did not differ significantly (P>0.05) i.e. Nakitembe (5.37\%), Musakala (5.12\%) and Mpologoma (4.07\%). At stage 5, MeO was $4.73 \%$ for Nakitembe, $7.27 \%$ for Musakala and 5.73\% for Mpologoma and was not significantly different ( $\mathrm{P}>0.05)$. At stage 7 of ripening, $\mathrm{MeO}$ of the pectin from Nakitembe was $11.02 \%$, from Musakala was $8.76 \%$ and Mpologoma 7.88\%. The pectin from banana peel at stage 2 of ripening had low methoxyl content of $4.02 \%$ for Nakitembe, $5.86 \%$ for Musakala and 4.03\% for Mpologoma. At stages 5 and 7, the respective MeO contents of the pectin extracts were $5.87 \& 3.67 \%$ for Mpologoma; $4.02 \& 8.21 \%$ for Nakitembe and $7.13 \& 7.75 \%$ for Musakala. 

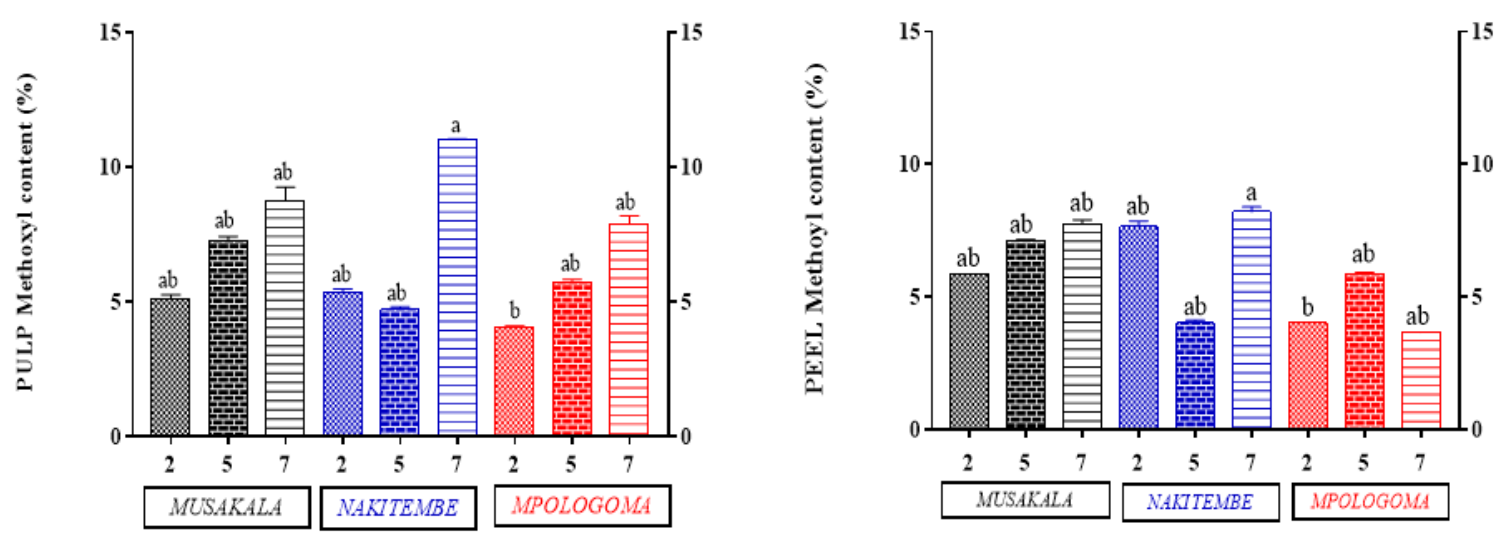

Figure 4. Methoxyl content of pectin extracted from pulp and peel of selected cooking banana cultivars at different stages of ripening

Different letters above each bar show significant difference at $(\mathrm{p}<0.05)$.

\subsubsection{Anhydrouronic Acid (AUA) Content}

The AUA content of pectin from ripening bananas ranged from 24.51 to $67.38 \%$ generally increasing with the stage of ripening depending on the banana cultivar (Figure 5). There was no significant difference in the AUA $(\mathrm{P}>0.05)$ of pectin extracted from banana pulp and peel across the ripening stages. AUA of pectin from banana pulp generally increased with increase in ripening. For instance, Nakitembe increased from 39.41 to $67.38 \%$, Musakala increased from 37.67 to $58.57 \%$ and Mpologoma increased from 24.51 to $48.64 \%$. AUA of pectin from the peel increased from 26.48 to $53.49 \%$ for Nakitembe, 43.15 to $53.94 \%$ for Musakala while that for pectin from Mpologoma remained almost the same (24.64 to 23.60\%). Generally, pectin from pulp had a higher AUA content than that from the peel.
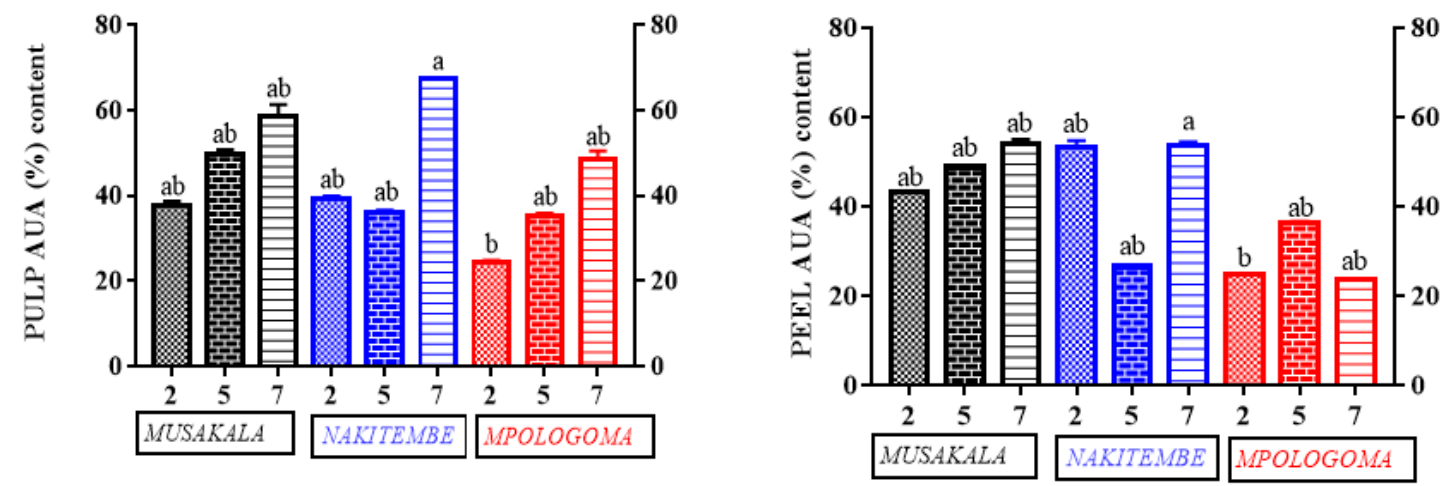

Figure 5. Anhydrouronic acid (AUA) content of pectin extracted from pulp and peel of selected cooking banana cultivars at different stages of ripening

Different letters above each bar show significant difference at $(\mathrm{P}<0.05)$.

\subsubsection{Degree of Esterification (DE)}

The DE of pectin extract from ripening banana pulp and peel was generally very high and ranged between 77 to 94\% (Figure 6) implying high methoxyl pectin. There was no significant difference ( $>>0.05)$ in the DE of pectin from the peel and pulp across all the stages of ripening. 

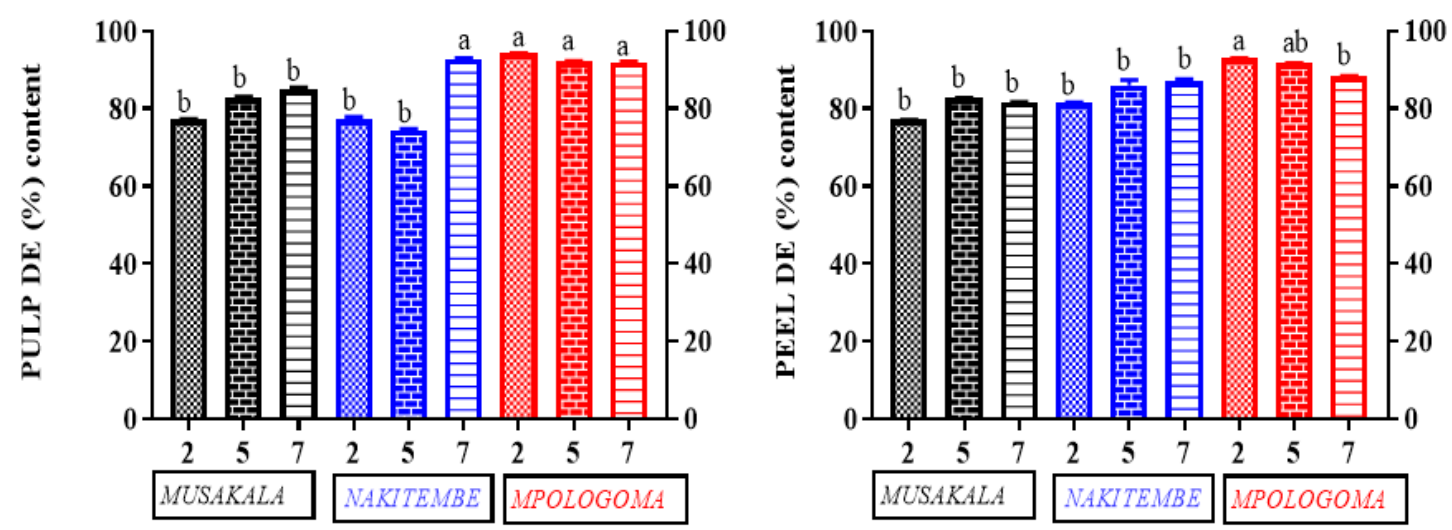

Figure 6. Degree of Esterification (DE) of pectin extracted from the pulp and peel of selected cooking banana cultivars at different stages of ripening

Different letters above each bar show significant difference at $(\mathrm{P}<0.05)$.

\subsubsection{Ash Content}

The ash content of banana pectin extracted from peel and pulp ranged between 0.3 and $5.4 \%$. There was no significant difference $(\mathrm{P}>0.05)$ between the ash content of pectin extracted from the peel and pulp across the ripening stages (Figure 7).
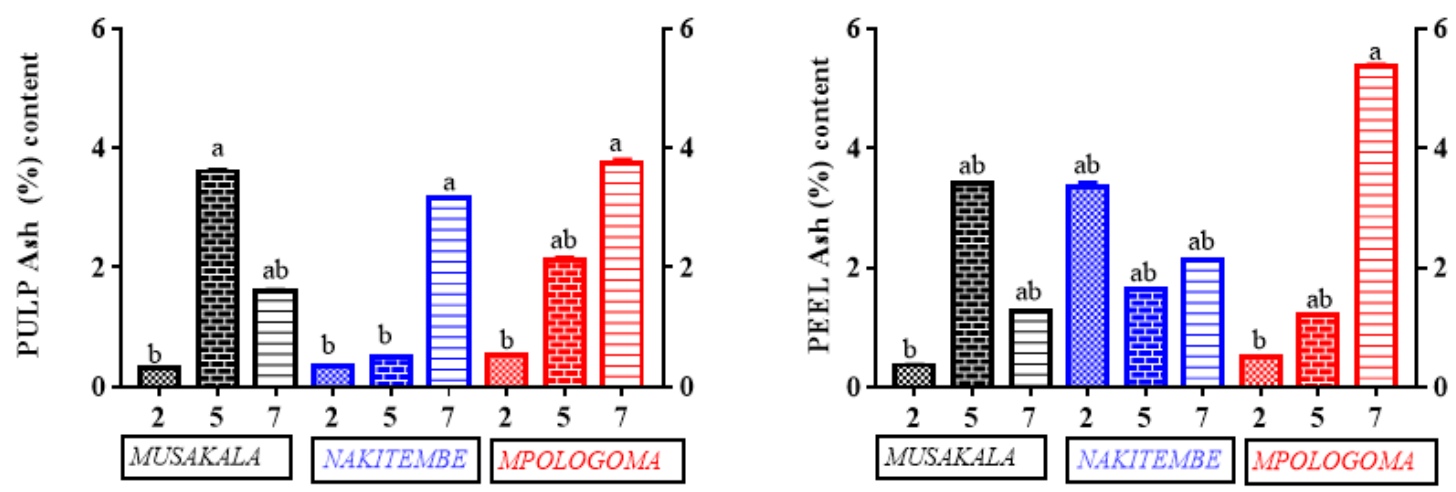

Figure 7. Ash content of pectin extracted from the pulp and peel of selected cooking banana cultivars at different stages of ripening.

Different letters above each bar show significant difference at $(\mathrm{P}<0.05)$.

\section{Discussion}

\subsection{Pectin Yield}

The high pectin yield at green maturity (stage 0 ) and at stages 1 and 2 of ripening could be due to presence of protopectin (pectin combined with hemicellulose, cellulose, lignin and starch) (Castillo-Israel et al., 2015; Conrad, 1930). According to these authors, the maturity stage of bananas affects pectin yield as the amounts of pectin, hemicellulose, cellulose and lignin vary as the fruit matures. These authors found higher pectin yield of about $16.5 \%$ from Saba banana peels at the unripe stage compared to $11.87 \%$ from the same bananas at the ripe stage. The high ionic strength of $\mathrm{HCl}(\mathrm{pH} 2.2)$ also maximizes extraction and precipitation of pectin and impurities including other negatively charged ionic molecules such as cellulose and hemi-cellulose. High extraction temperatures have also been reported to increase extraction yield (Gama, De Farias Silva, Oliveira Da Silva, \& Abud, 2015). Uzma, Genitha, \& Farheena (2015) obtained the highest percentage of pectin (16\%) from papaya peels on extraction with hydrochloric acid at $\mathrm{pH} 2.0$, temperature of $80^{\circ} \mathrm{C}$ for $60 \mathrm{~min}$ of extraction, similar to the conditions used in this study. Yadav, Khan, Kunjwani, \& Mular (2015) obtained pectin yield of up to $36 \%$ from orange peels using $\mathrm{HCl}$ at $\mathrm{pH} 2$ and $85^{\circ} \mathrm{C}$ extraction conditions. However, the yield of pectin decreased with ripening which could be explained by the increasing hydrolysis of protopectin releasing cellulose, 
hemicellulose and lignins as bananas ripen. Pectin content of fully ripe bananas has been reported to range between 0.5 to $1.28 \%$ (Baker, 2006), which is in agreement with pectin yield at ripening stages 5 and 7 of this study. Pectin yield generally increases at the expense of protopectin as fruits ripen due to increasingly weaker connections between pectin and other cellular compounds thus making pectin more available for extraction. However, over ripening of bananas like at stage 7 results into a decrease in pectin yield due to degradation of pectin by native pectolytic enzymes i.e. polygalacturonase, pectin methyl esterase and pectin lyase (Emaga, Adrianaivo, Wathelet, Tchangco, \& Paquot, 2007). These results imply that the stage of ripening has a significant influence on pectin yield and therefore, extraction could be optimized at stage 5 of ripening.

\subsection{Characterization of the Pectin}

\subsubsection{Equivalent Weight}

The equivalent weight (Eq. wt.) of pectin in the current study was generally high compared to literature values. Pectin produced at lower $\mathrm{pH}$ normally has a higher equivalent weight due to possible polymerization of the pectin molecules into longer chains (Uzma et al., 2015; Rouse, 1977). Equivalent weight represents the quantity of pectin that is reactive which can undergo cross-linking reactions through polyol functional groups and is indicative of a high degree of esterification which is in turn associated with a higher gelling power (Vaclavik \& Christian, 2008; Yadav et al., 2015; Ragab, Osman, Khalil, \& Gouda, 2016). The high eq. wt obtained in this study could imply strong associations between the pectin and cellulose/hemicellulose including other molecules. The high equivalent weights obtained in this study were in agreement with those reported by Castillo-Israel et al. (2015) in pectin from unripe banana peels. Therefore, the relatively high equivalent weight could be justified by the stage of maturity and ripening.

\subsubsection{Methoxyl Content}

Methoxyl content of banana pectin in this study increased with ripening. This means methoxyl content of pectin could be affected by the level of maturity of bananas. Castillo-Israel et al. (2015) while studying characteristics of pectin from Saba banana peels obtained methoxyl content of $6.4 \%$ and $5.25 \%$ in ripe and unripe bananas, respectively. According to Aina, et al. (2012), the methoxyl content of extracted pectins varies between 0.2 and $12 \%$ depending on the source and mode of extraction implying that the methoxyl content obatined in this study was within range at all stages of ripening. Methoxyl content of commercial pectins varies from 8-11\% (Castillo-Israel et al., 2015). The methoxyl content of most pectin extracts in this study was above 6.4\% meaning that they were high methoxyl pectins (Beda \& Kouassi, 2014; Castillo-Israel et al., 2015) and therefore, could form strong gels with sugar especially pectins with methoxyl content above 7\% (Genovese, Ye, \& Singh, 2010). Pectins with methoxyl content less than 7\% can form gels with lower concentrations of sugar. High methoxyl content may also imply strong adhesive and cohesive forces which could imply increased firmness of the gels. Methoxyl content is important in controlling setting time of pectin, sensitivity to polyvalent metal cations and also determines the functional properties of the pectin-gel texture (Constenla \& Lozano, 2003). It also affects the dispersability of pectin in water where pectin with high methoxyl content $(>7 \%)$ is readily dispersible in water (Rouse et al., 1962). Therefore, these pectins are suitable for industrial use particularly in jam and jelly production. Our results imply that banana pectin particularly that from the pulp at stage 7 could be suitable for industrial use such as in production of jam and jellies while the low methoxyl pectin at stages 2 and 5 (pulp) and that from peel could be used in production activities where weaker gels are required such as yogurt.

\subsubsection{Anhydrouronic Acid (AUA)}

The AUA values of pectin from green mature and ripe bananas examined in this study were in agreement with values obtained by Castillo-Israel et al. (2015) of 57.3\% and $39.68 \%$ for ripe and unripe banana peels, respectively. The results were also similar to those reported by Khamsucharit, Laohaphatanalert, Gavinlertvatana, Sriroth, \& Sangseethong (2018) for pectin from peels of Kluai Hin (34.56 \%) and Kluai Nam Wa (66.67\%) banana cultivars from Thailand. AUA is an indicator of the purity and degree of esterification of pectin (Rangana, 1986). Pectin normally contains about $10 \%$ or more organic materials (Assifaoui, et al., 2015). Pectin with AUA of less than 65\% may indicate impurities due to presence of proteins, starch and sugars (Norazelina \& Nazarrudin, 2011). The recommended AUA (\%) for extracted pectin for use in pharmaceuticals and as a food additive should not be less than 65\% (May, 1990). The generally low AUA content in this study implies low purity of extracted pectin hence requiring further purification if the pectin is to be used commercially. According to Castillo-Israel et al. (2015), longer extraction times could be adopted for higher values of AUA. Pectin extracted at stages 2 and 5 had relatively lower AUA compared to that extracted at stage 7. Results in Figure 5 generally indicated that pectin extracted at stage 7 of ripening had a higher AUA implying increasing purity with ripening. Values of AUA for pectin from green mature bananas were also comparable with values from ripe 
bananas. Pectin from the pulp seemed to be much purer relative to that from the peel.

\subsubsection{Degree of Esterification}

$\mathrm{DE}$ is important in determining the gelling and adhesive power of pectin and in case of plant tissue pectin, it has been given in the range of $60-90 \%$ (Shaha, Nayagi, Punichelvana, \& Afandi, 2013). High DE was observed in pectin from ripe bananas and there was no significant difference in DE with respect to the stage of ripening. However, the degree of esterification differs depending on the level of maturity or ripeness, part of the fruit, botanical source and method of isolation (Bonrood, Kamonrad, \& Niamsupn, 2005). During ripening, solubility of pectic substances increases mainly due to activity of pectic enzymes i.e. polygalacturonase (PG) and pectin methylesterase (PME) (Maduwanthi \& Marapana, 2017). The banana pectin in this study can be categorized as rapid set pectin since it had DE greater than $72 \%$ (Shaha et al., 2013). Our DE values were within the DE range of 60 to 90\% generally found in pectin from plant tissues (Shaha et al., 2013). The high DE implies high gelling power of the extracted pectin which is a good indicator for commercial application such as use in the manufacture of jams and jellies.

\subsubsection{Ash Content}

The ash content of all pectin extracts from the three banana cultivars from peel and pulp was less than 5.5\%. This means that their purity was acceptable for commercial application (Khamsucharit et al., 2016; Shaha et al., 2013). To form gels of good quality, the maximum limit for ash content in pectin should not exceed $10 \%$ (Norazelina et al., 2011). Overall, pectin from Mpologoma peel at stage 7 contained the highest amount of ash indicating that it could produce the least quality pectin among the banana cultivars.

\section{Conclusion}

The high methoxyl content and degree of esterification of the pectin extracted from Ugandan cooking bananas implies high gelling power which makes it suitable for commercial application in industry particularly in the production of jams and jellies. If extracted at stages 2 and 5 , the pectin could be used in products such as yogurt that do not require high levels of setting. Both peel and pulp could be good sources of high quality pectin due to its relatively high degree of esterification. Moreover, purity of the pectin appeared to increase with stage of ripening as observed with AUA implying higher quality pectin could be extracted from bananas at stage 5 and above.

\section{Acknowledgement}

This work was funded by Kyambogo University under the Competitive Research Grants in the Fiscal Year 2019-2020. Authors are very grateful to Mr. Ivan Kiganda Sembatya (Department of Chemistry, Kyambogo University) and Hezron (Kenya Bureau of Standards) for their technical assistance.

\section{References}

Aina, V., Barau, M., Mamman, O., Zakari, A., Haruna, H., ... Hauwa, U. M. (2012). Extraction and characterization of pectin from peels of lemon (Citrus limon), grape fruit (Citrus paradise) and sweet orange (Citrus sinensis). British Journal of Pharmacology and Toxicology, 3(6), 259-262.

Arumugam, R., \& Manikandan, M. (2011). Fermentation of pretreated hydrolyzates of banana and mango fruit wastes for ethanol production. Asian Journal of Experimental Biological Sciences, 2(2), 246-256.

Assifaoui, A., Lerbret, A., Uyen, H., Neiers, F., Chambin, O., Loupiacac, C., \& Cousinc, F. (2015). Structural behaviour differences in low methoxy pectin solutions in the presence of divalent cations $(\mathrm{Ca} 2+$ and $\mathrm{Zn} 2+)$ : a process driven by the binding mechanism of the cation with the galacturonate unit. Journal of soft matter, 11(3), 551-560. https://doi.org/10.1039/C4SM01839G

Baker, A. R. (2006). Reassessment of Some Fruit and Vegetable Pectin Levels. A critical review. . Journal of Food Science, 62(2), 225-229. https://doi.org/10.1111/j.1365-2621.1997.tb03973.x

Beda, M., \& Kouassi, L. (2014). Extraction and Characterization of Highly Gelling Low Methoxy Pectin from Cashew Apple Pomace. Foods, 3, 1-12. https://doi.org/10.3390/foods3010001

Bonrood, D., Kamonrad, R., \& Niamsupn, H. (2005). Extraction and Physicochemical Characteristics of Acid Soluble Pectin from Raw Papaya (Carica papaya) Peel. Chiang Mai Journal of Science, 33(1), 129-135.

Castillo-Israel, K., Diasanta, S., Lizardo, M., Dizon, R., \& Mejico, M. (2015). Extraction and characterization of pectin from Saba banana [Musa 'saba' (Musa acuminata x Musa balbisiana)] peel wastes: A preliminary study. . International Food Research Journal, 22(1), 202-207.

Conrad, C. (1930). A furfural-yielding substance as a splitting product of protopectin during the ripening of fruits. 
Plant Physiology, 5, 93-103. https://doi.org/10.1104/pp.5.1.93

Constenla, D., \& Lozano, J. (2003). Kinetic model of pectin demethylation. Latin American Applied Research, 33, 91-96.

Emaga, H., Adrianaivo, R., Wathelet, B., Tchangco, J., \& Paquot, M. (2007). Effect of the stage of maturation and varieties on the chemical composition of banana and plantain peels. Food Chemistry, 103(2), 590-600. https://doi.org/10.1016/j.foodchem.2006.09.006

Gafuma, S., Byarugaba-Bazirake, G., \& Mugampoza, E. (2018). Textural Hardness of Selected Ugandan Banana Cultivars under Different Processing Treatments. Journal of Food Research, 7(5). https://doi.org/10.5539/jfr.v7n5p98

Gama, B., De Farias Silva, C., Oliveira Da Silva, L., \& Abud, A. (2015). Extraction and characterization of pectin from citric waste. Chemical Engineering Transactions, 44, 259-264. https://doi.org/10.3303/CET1544044

Genovese, D., Ye, A., \& Singh, H. (2010). High Methoxyl Pectin/Apple Particles Composite Gels: Effect of Particle size and particle concentration on mechanical properties and gel structure. Journal of Texture Studies, 41(2), 171-189. https://doi.org/10.1111/j.17454603.2010.00220.x

Kabahenda, M., Kapiriri, M., Egeru, A., Majaliwa, J. G., Isubikalu, P., Mukwaya, P., \& Bukenya, M. (2010). Analysing the agricultural science and technology innovation systems: A case study of banana sub-sector in Uganda. Technical Centre for Agricultural and Rural Cooperation (CTA) and Regional Universities Forum for Capacity building in Agriculture (RUFORUM).

Khamsucharit, P., Laohaphatanalert, K., Gavinlertvatana, P., Sriroth, K., \& Sangseethong, K. (2018). Characterization of pectin extracted from banana peels of different varieties. Journal of Food Science and Biotechnology, 27(3), 623-629. https://doi.org/10.1007/s10068-017-0302-0

Maduwanthi, S., \& Marapana, R. (2017). Biochemical changes during ripening of banana: A review. . International Journal of Food Science and Nutrition, 2(5), 166-170. https://doi.org/10.22271/food

May, C. (1990). Industrial Pectins: Sources, Production and Applications. Carbohydr Polym, 12, 79-99. https://doi.org/10.1016/0144-8617(90)90105-2

Min, B., Lim, J., Ko, S., Lee, K., Lee, S., \& Lee, S. (2011). Environmentally friendly preparation of pectins from agricultural byproducts and their structural/rheological characterization. Bioresource Technology, 102(4), 3855-60. https://doi.org/10.1016/j.biortech.2010.12.019

Naggarajaiah, S., \& Prakash, J. (2011). Chemical composition and antioxidant potential of peels from three varieties of banana. Asian Journal of Food Agro-Industries, 4, 31-46.

Norazelina, S., \& Nazarrudin, R. (2011). Extraction and characterization of pectin from dragonfruit (Hylocereus polyrrhizus) using various extraction conditions. Malaysia: Sains Malaysiana, 41(1), 41-45.

Owens, H., McCready, R., Shepherd, A., Schultz, S., Pippen, E., Swenson, H., ... Maclay, W. (1952). Methods used at Western Regional Research Laboratory for extraction and analysis of pectic materials. AIC-340 Western Regional Research Laboratory, Albany, California.

Parre, E., \& Geitmann, A. (2005). Pectin and the role of the physical properties of the cell wall in pollen tube growth of Solanum chacoense. Planta, 220(4), 582-592. https://doi.org/10.1007/s00425-004-1368-5

Pratik, B., Sheetal, G., \& Teja, S. (2017). Extraction of Pectin from Unripe Banana Peel. International Research Journal of Engineering and Technology (IRJET), 4(7), 2259-2264.

Ragab, M., Osman, M. F., Khalil, M. E., \& Gouda, M. S. (2016). Banana (Musa sp.) peels as a source of pectin. Journal of Agricultural Research. Kafr El-Sheikh Univ., 42(4), 88-102. https://doi.org/10.21608/jsas.2016.3028

Rangana, S. (1986). Handbook of analysis and quality control for fruit and vegetable products. New Dehli. 1112p: Tata Mc Graw-Hill Publishing Company.

Rouse, A. (1977). Pectin: distribution, significance. In S. D. Nagy, E. Shaw \& M. Veldhuis (Eds.), Citrus Science and Technology. The AVI Publishing Company Inc.

Shaha, R., Nayagi, Y., Punichelvana, A., \& Afandi, A. (2013). Optimized Extraction Condition and Characterization of Pectin from Kaffir Lime (Citrus hystrix). Research Journal of Agriculture and Forestry Sciences, 1, 1-11. 
Uzma, A., Genitha, I., \& Farheena, I. (2015). Extraction and characterization of pectin derived from papaya (Carica papaya Linn.) peel. International Journal of Science, Engineering and Technology, 3(4), 970-974. https://doi.org/10.2348/ijset07150970

Vaclavik, V., \& Christian, E. (2008). Essentials in Food Science (3rd ed.). USA: Springer Science + Business.

Wang, S., Chen, F., Wu, J., Wang, Z., Liao, X., \& Hu, X. (2007). Optimization of pectin extraction assisted by microwave from apple pomace using response surface methodology. Journal of Food Engineering, 78, 693-700. https://doi.org/10.1016/j.jfoodeng.2005.11.008

Yadav, S., Khan, Z., Kunjwani, S., \& Mular, S. (2015). Extraction and characterization of Pectin from different fruits. Journal of Applied Research, 1(9), 91-94.

\section{Copyrights}

Copyright for this article is retained by the author(s), with first publication rights granted to the journal.

This is an open-access article distributed under the terms and conditions of the Creative Commons Attribution license (http://creativecommons.org/licenses/by/4.0/). 